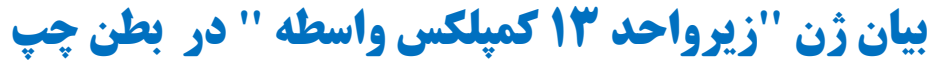

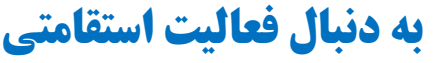

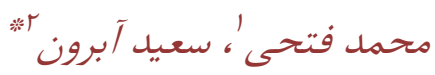

'استاديار گروه تربيتبدنى و علوم ورزشى، دانشكده علومانسانى، دانشگاه لرستان، خرم آباد، ايران.

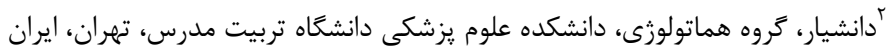
"نويسنده مسئول: تهران، تقاطع بزرگراه شهيد جمران-جلال آل احمد، دانشعاه تربيت مدرس،

دانشكده علوم يزشكى، عروه هماتولوزى. يست الكترونيك: abroun@modares.ac.ir

דكب.

زمينه و هدف: فعاليت /ستقامتى و "زير واحد با ا كميلكس واسطه" تاثير قابل ملاحظهاى بر ساختار و بافت قلب

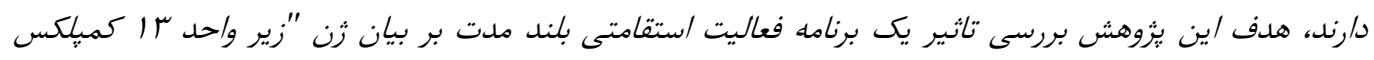

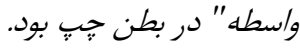

مواد و روش كار: عأ رت تحت شرايط استاندارد نكهدارى و بعد /ز آشناسازى با بروتكل تمرينى به صورت

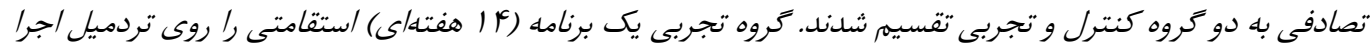

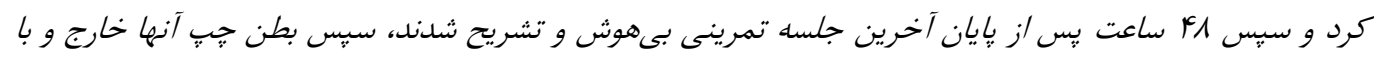

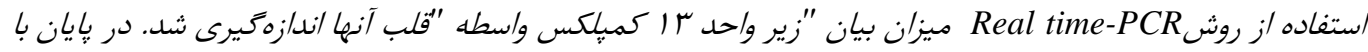

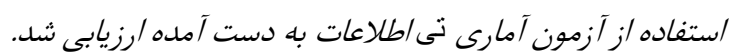

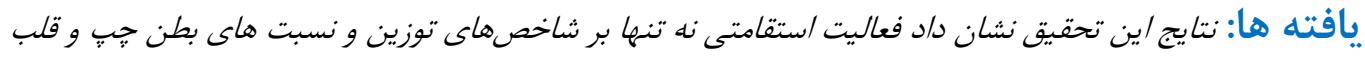

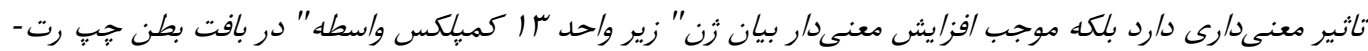
هاى تمرينكرده مى شود.

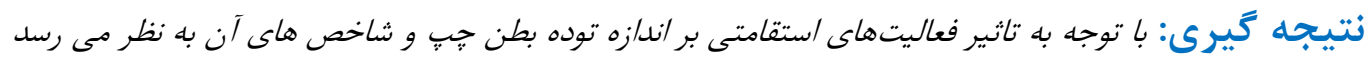

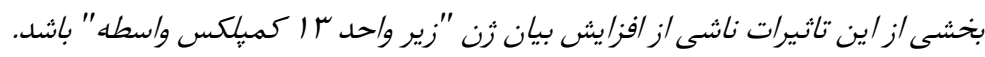

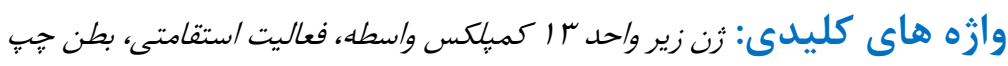

وصول: اصلاح: : 
فاكتور "زير واحد سا كميلكس واسطه "(med13) كه آن

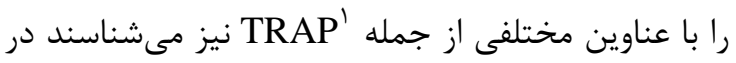

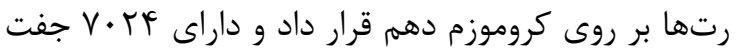

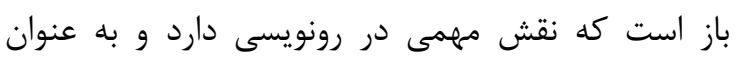

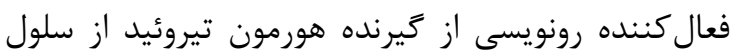

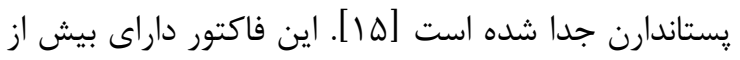

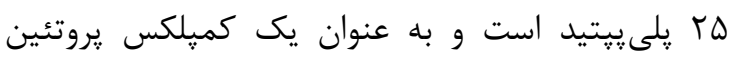

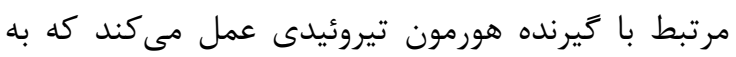

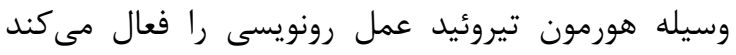

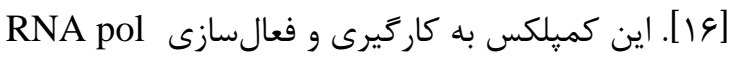
و دII

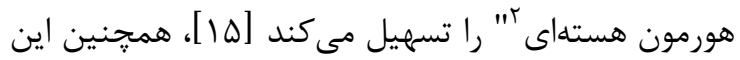

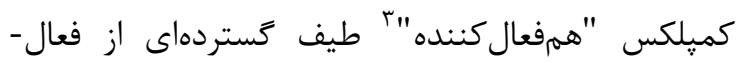

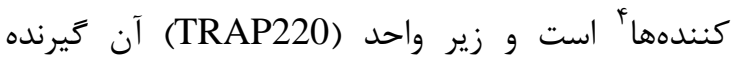
تيروئيد را با ديخر كيرندهاى هستهاى مرتبط مى كند

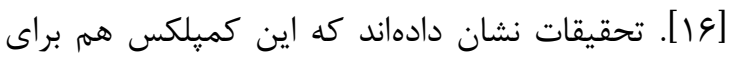

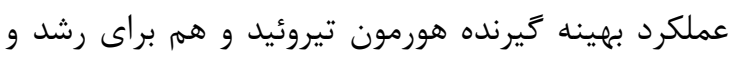

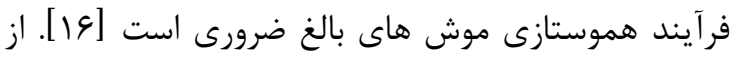
آنجايى كه هم فعاليت بدنى و هم فاكتور

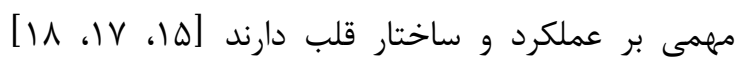

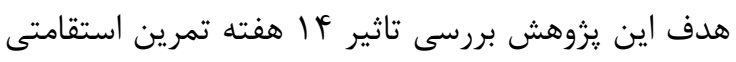
بر بيان زن med13 بافت بطن جِ رته رتهاى نر نزاد ويستار

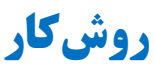

يزوهش حاضر اثر أl هفته فعاليت استقامتى بر بيان زن med13 عضله قلب را به روش تجربى ارزيابى كرد. بدين

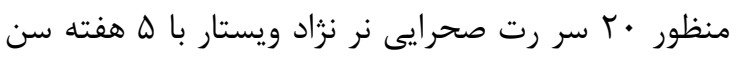

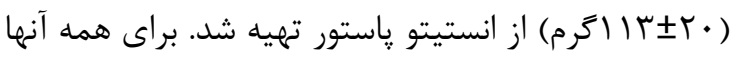
شرايط مناسب آزمايشأهى (دسترسى آزاد به آب و غذا ندا

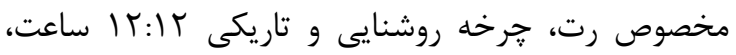

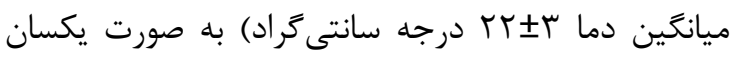

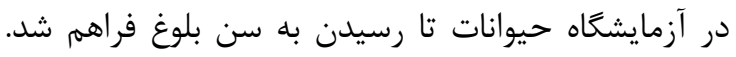

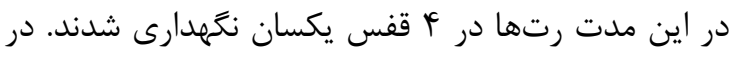

1- Thyroid Hormone Receptor (TR) AssociatedProtein

2- Nuclear Hormone Receptor target genes

3- Coactivator

4- Activators 
fl حفظ شد. يروتكل بين ساعات ه تا V بعد ازظهر هر

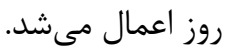

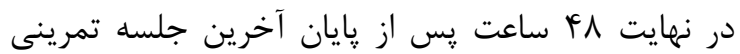

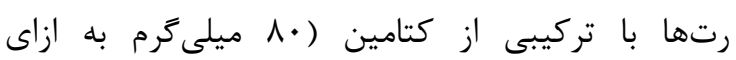

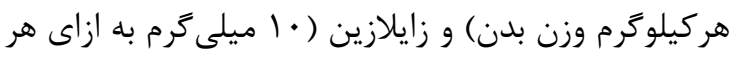

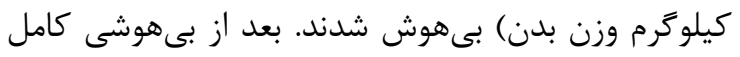

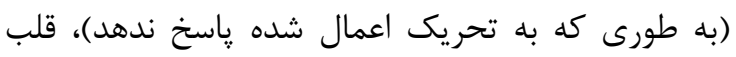

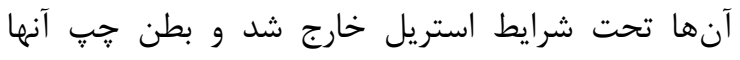
توسط متخصص آناتومى جدا شد. بافت مورد نظر (بطن

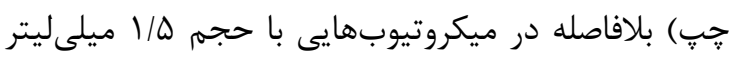

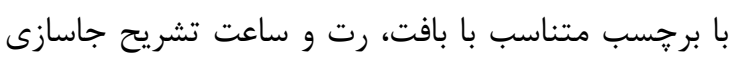

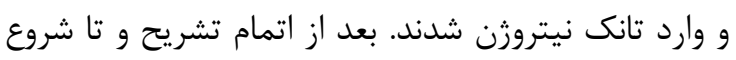

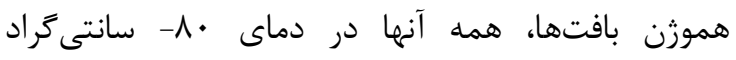

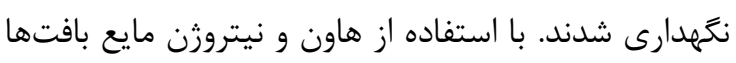

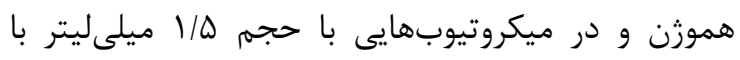
برجسب مناسب نَخهدارى شدند.

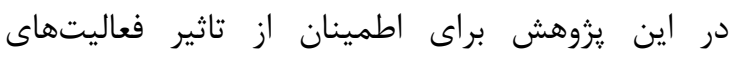

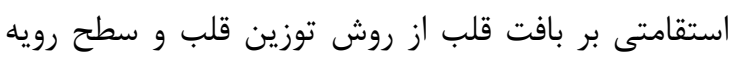
بدن ' (BSA) استفاده شد. متخصص تشريح، قلب حيوان

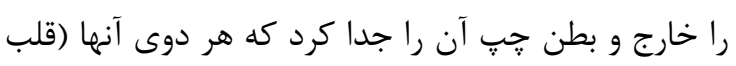

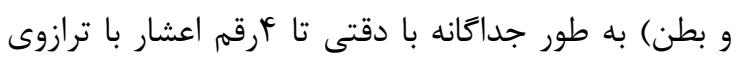

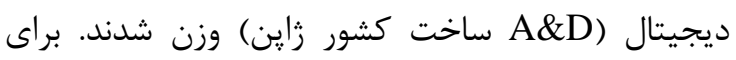

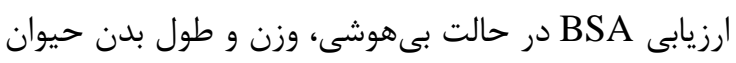

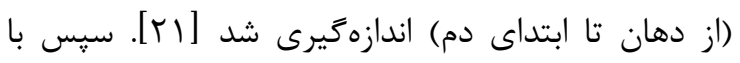

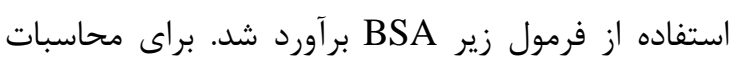

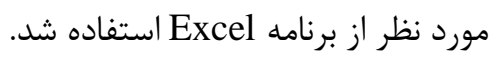
$\mathrm{BSA}=6.67 \times \mathrm{W}^{0.7} \times[0.34 /(\sqrt[3]{W} / L)] .\left[r_{1}\right]$

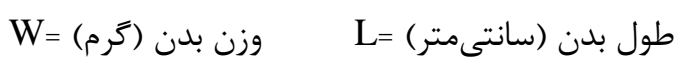

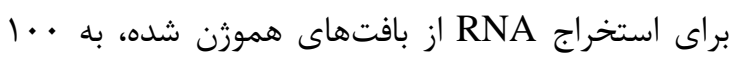
ميلى

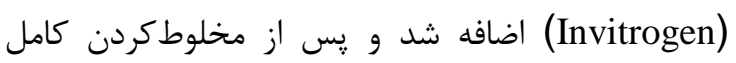

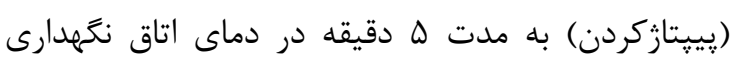

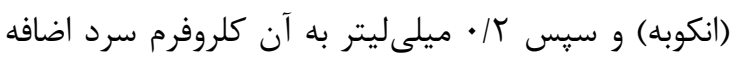

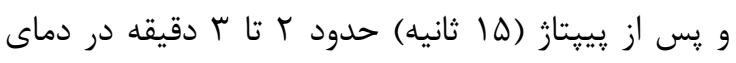

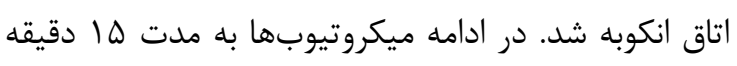

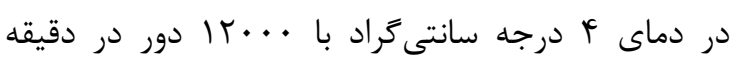

\section{1-Body Surface Area}

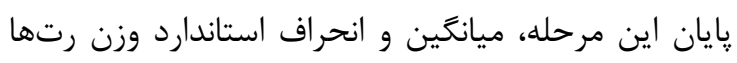

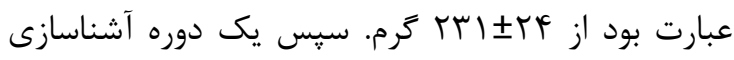

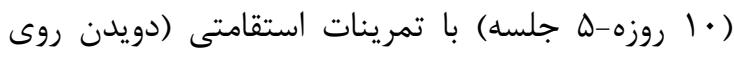

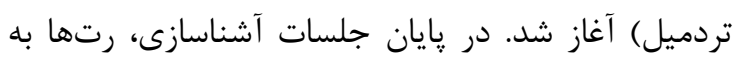

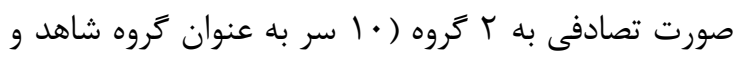

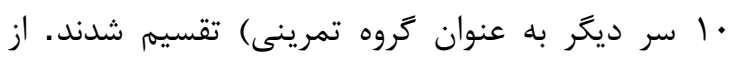

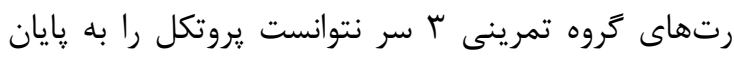

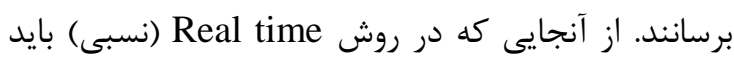

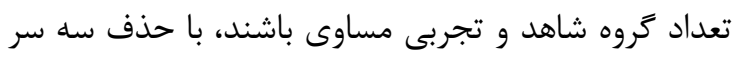

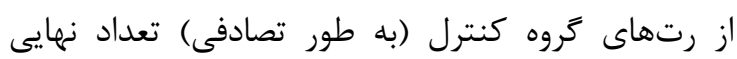

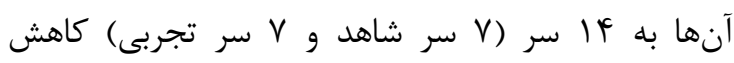

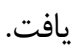

با استفاده از منابع ييشين يك يروتكل تمرين استقامتى

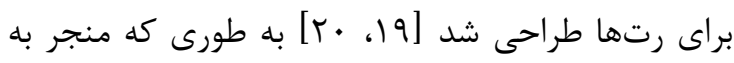
هاييرتروفى قلب و بطن جِ

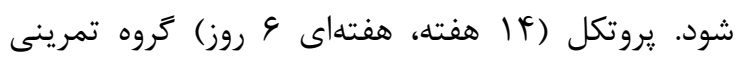

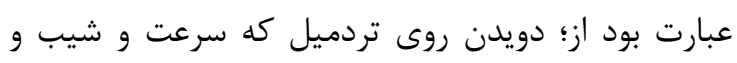

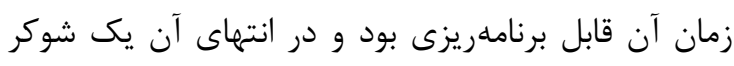

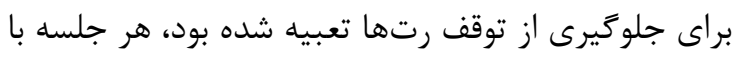

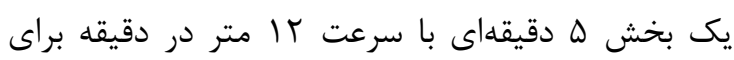

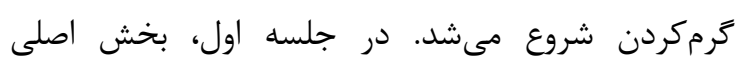

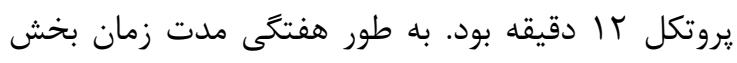

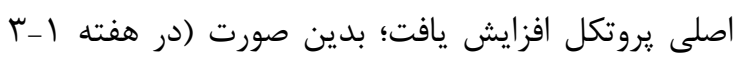

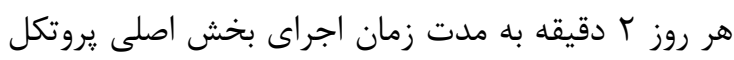

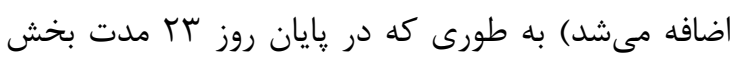

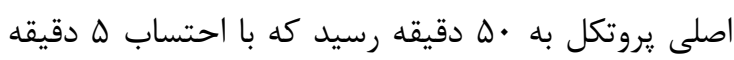

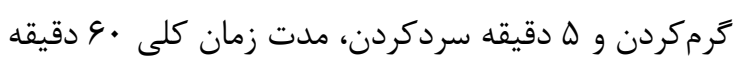

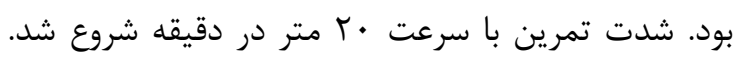

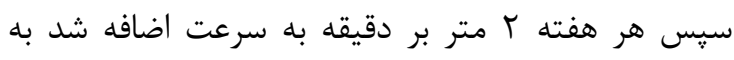

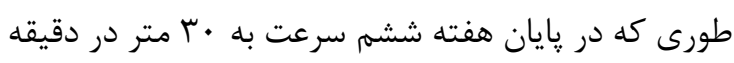

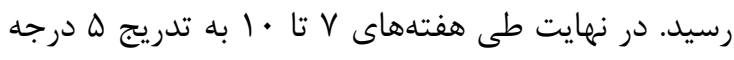

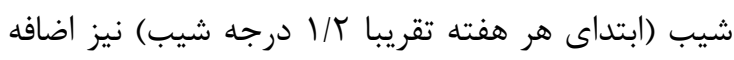

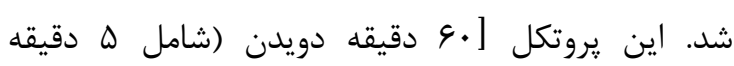

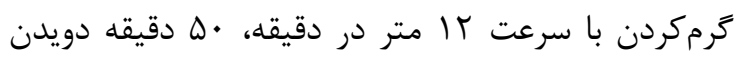

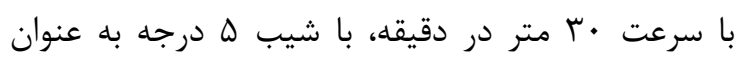

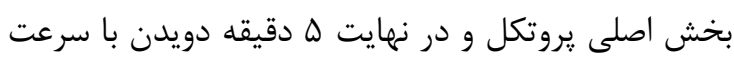

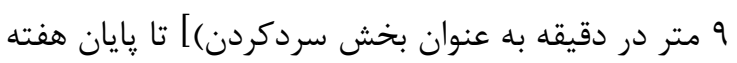


ابتدا : برايمر زنها توسط نرم افزار Oligo7 طراحى و سو توسط شركت Gene Biotech سنتز شدند. قبل از

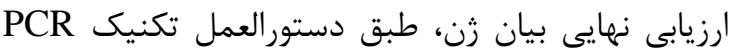

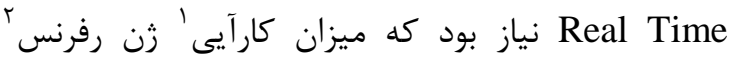

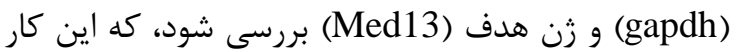

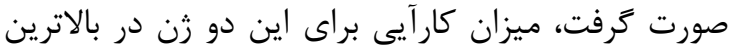

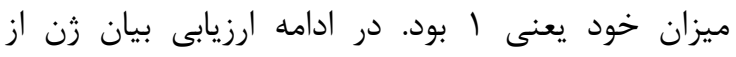
تكنيك one step) Real Time PCR و دستكاه شركت آل

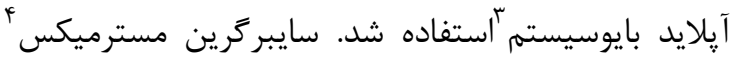

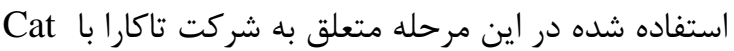

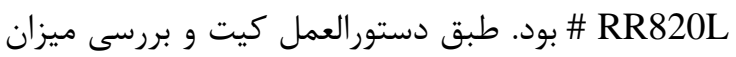

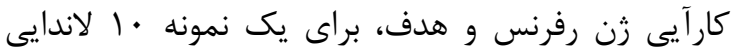

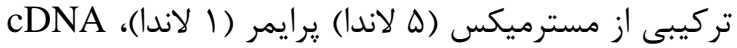

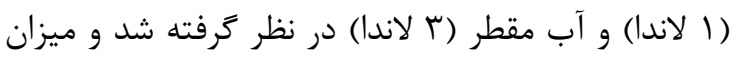
بيان زن با استفاده از روش نسبى ارزيابى شد. در هر الآندان

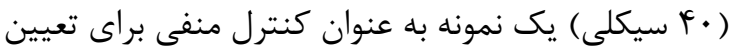
آلودكى master mix (طبق دستورالعمل شركت بـ آنلايد

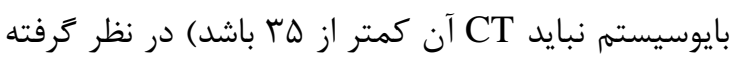
شد. و كنترل داخلى (gapdh)، كنترل مثبت (كروه

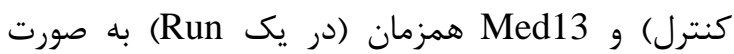

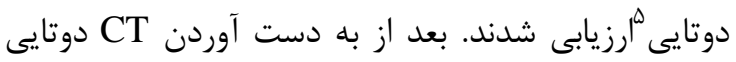
براى هر نمونه ميانگين آنها محاسبه شد. بعد از انتقال

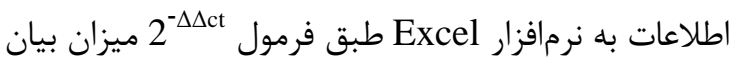

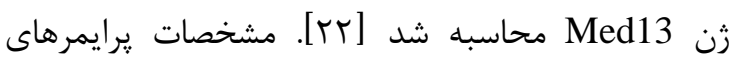
استفاده شده در جدول ا آمده است. زن رفرنس مطابق

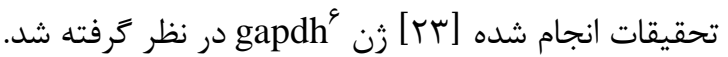
دادهاى به دست آمده از دستكاه RealTimePCR كه به

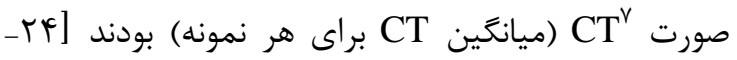

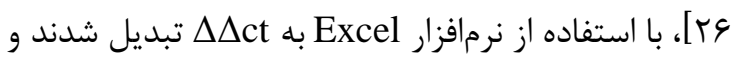
سيس با استفاده از فرمول

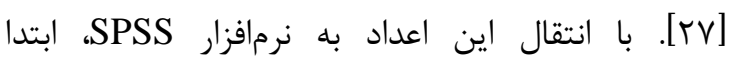

1-Efficiency

2- Housekeeping

3- Applied Biosystem

4- SYBR green master mix

5-Duplicate

6-Glyceraldehyde 3-Phosphate Dehydrogenase 7- Cycle threshold
سانتريفيوز (شركت eppendorff) شدند، سيس مايع رويى به دقت برداشته شد و به يك ميكروتيوب RNAase free

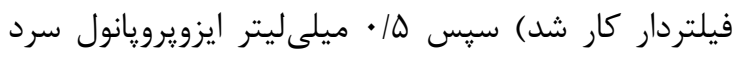

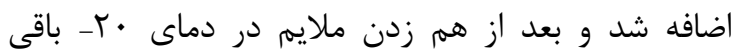

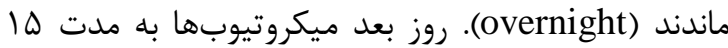

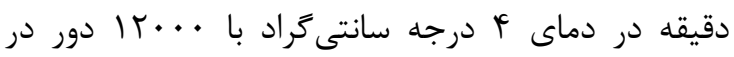
دقيقه مجددا سانتريفيوز شدند كه در اين مرحله يك دران رسوب سفيد رنگ در ته اكثر ميكروتيوبها قابل مشاهده

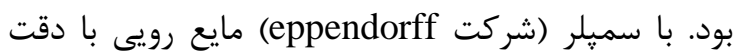

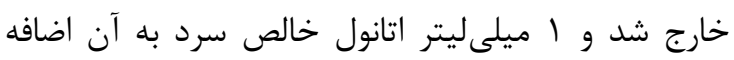

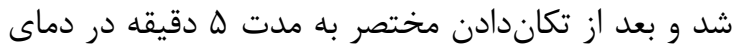
f

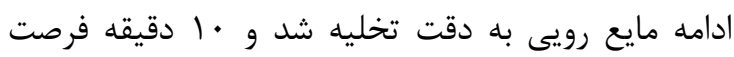
داده شد تا باقىمانده اتانول تبخير شود و و داخل ميكروتيوب خشك شود، بعد از اين مرحله •ه لاندا آب آب آنا

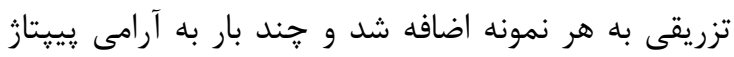

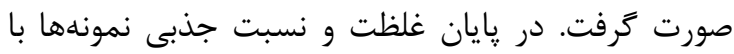
استفاده از دستگاه اسيكتروفتومتر (شركت Eppendorff)

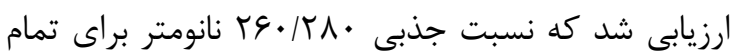

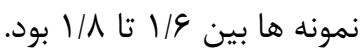
براى رونويسى RNA به ScientificThermo مطابق دستورالعمل كيت، مقدارى مشخصى از RNA هر نمونه، Random ،dNTP mix 'Reaction buffer

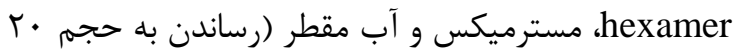
لاندا) در داخل يك ميكروتيوب براى هر نمونه تركيب (رسن

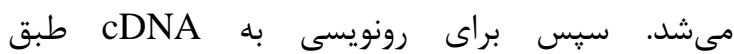
دستورالعمل كيت، دماى دستگاه ترموسايكلر به صورت زير براي برنامهريزى و اجراى مىشد. مرحله اول denaturation

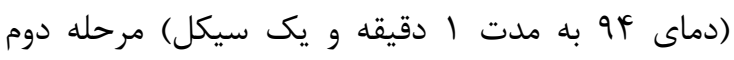

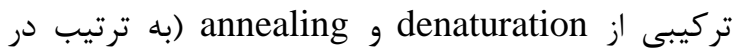

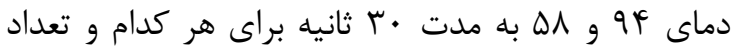

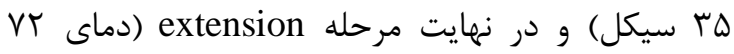
درجه به مدت دستورالعمل شركت سازنده انجام شد. ترموسايكلر مورد

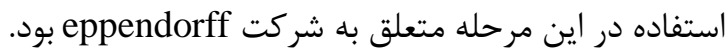


جدول 1: مشخصات يرايمرهاى مورد استفاده در يزوهش

\begin{tabular}{|c|c|c|c|c|}
\hline محصول & رفرنس توالى در سايت & 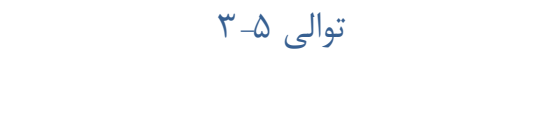 & & 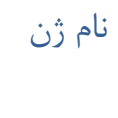 \\
\hline \multirow{2}{*}{ VF } & \multirow[t]{2}{*}{ NM_017008.4 } & AACCCATCACCATCTTCCAG & $\mathrm{F}$ & \multirow{2}{*}{$\begin{array}{c}\text { ز } \\
\text { gapdh }\end{array}$} \\
\hline & & CACGACATACTCAGCACCAG & $\mathrm{R}$ & \\
\hline \multirow[t]{2}{*}{ 1rq } & \multirow[t]{2}{*}{ NM_001107035.1 } & AGATGTACTCGGTGTTTGGC & $\mathrm{F}$ & زن \\
\hline & & GCCATTCTCCCATACTCCATC & $\mathrm{R}$ & Med13 \\
\hline
\end{tabular}

نتايج اين يزوهش نشان داد كه فعاليتهاى استقامتى

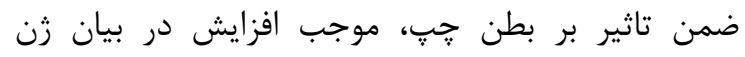
مed13

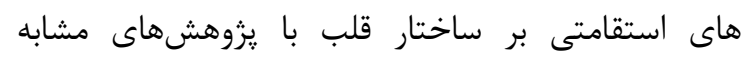

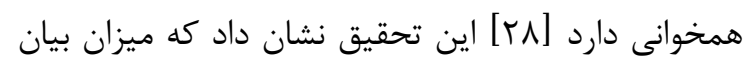

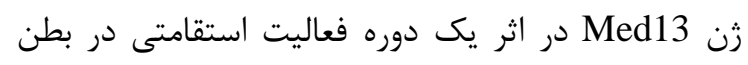

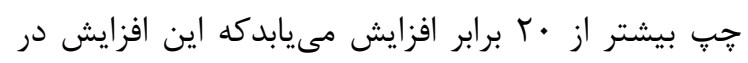

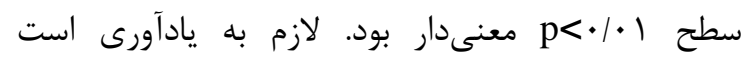

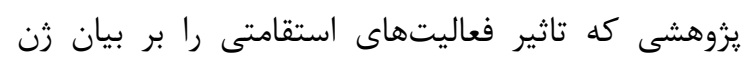

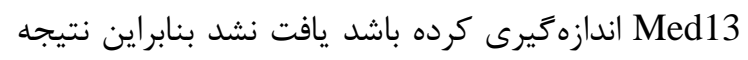

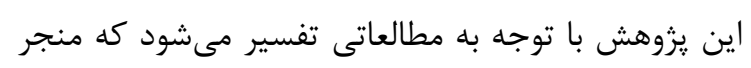

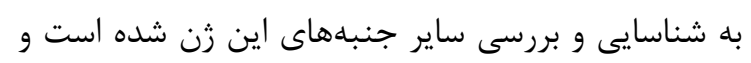

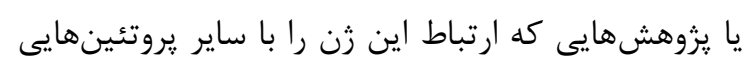

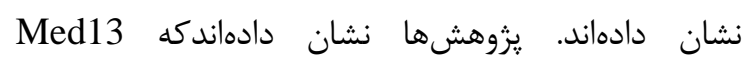

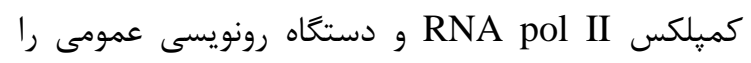
تسهيل مى كند [10] و طيف گستردهاى از فعال كننده-

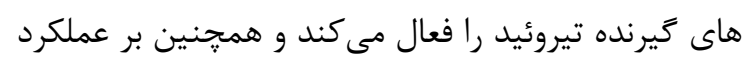

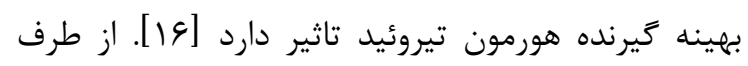

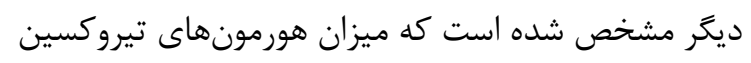

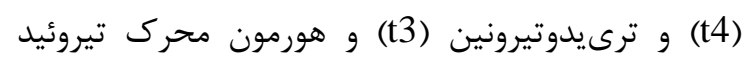

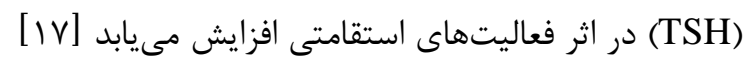

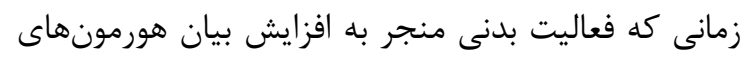

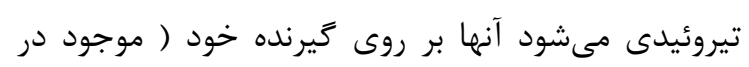

Shapiro- نرمالبودن توزيع دادهها با استفاده از آزمون

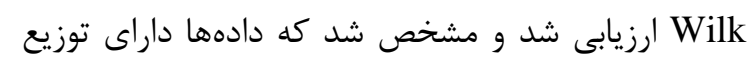

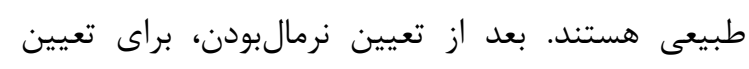
اختلاف ميانكَينها از آزمون t استفاده شد.

\section{يافته ها}

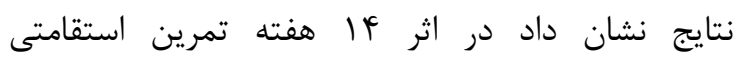
هاييرتروفى در بطن جٍ

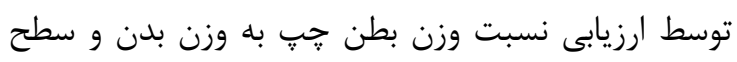

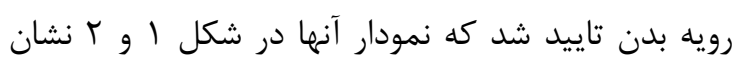

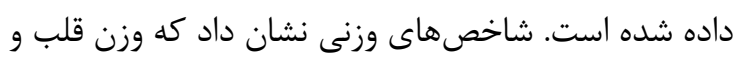

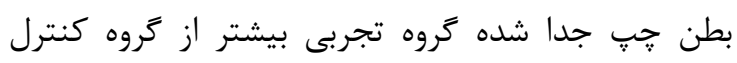

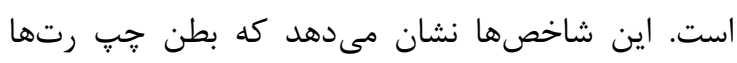

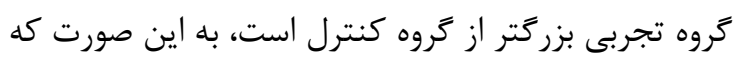

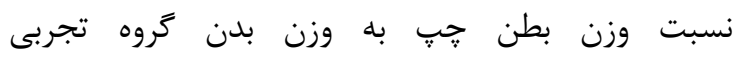

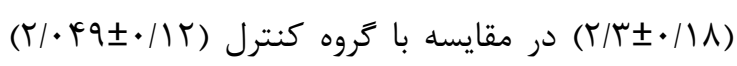

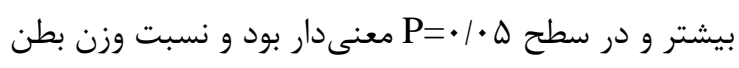

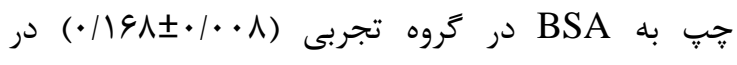

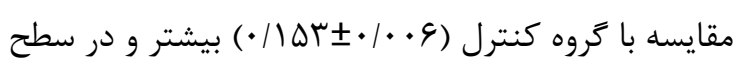
Pe معنى دار بود.

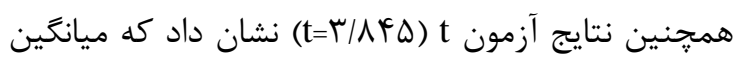

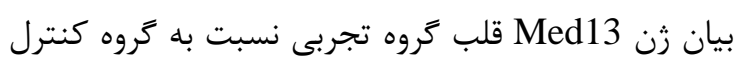

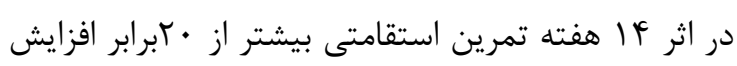

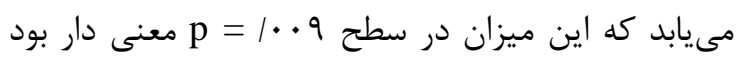

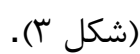




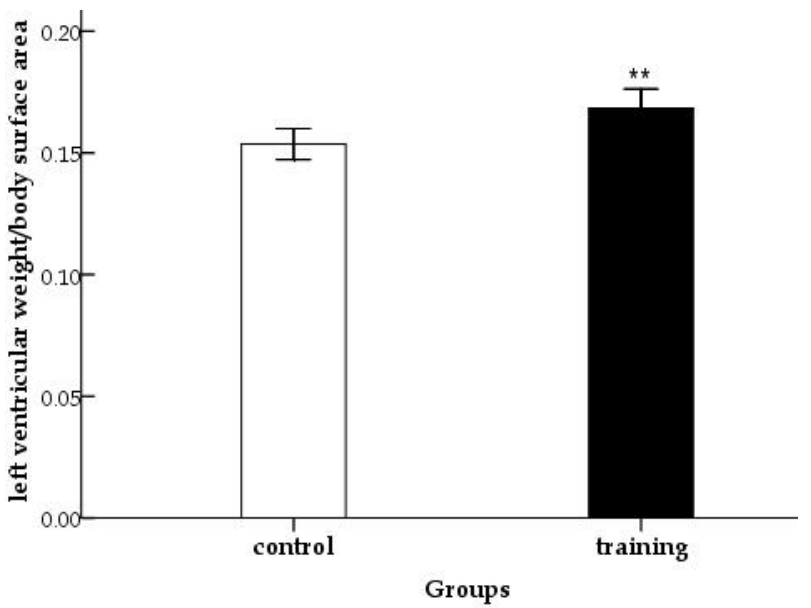

شكل ا: ارزيابى هايِرتروفى، نسبت وزن بطن جٍ به سطح رويه بدن در رتهايى كروه كنترل و تمرينى.

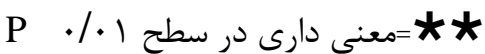

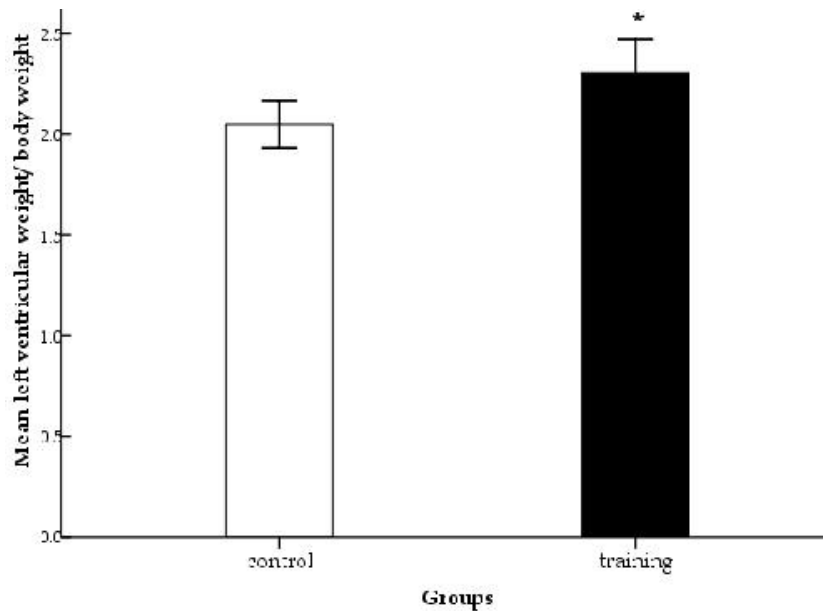

شكل ז: نتايج ميانكين نسبتهاى وزن بطن جِّ به وزن بدن در رتهايى گروه كنترل و تمرينى

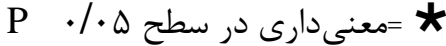

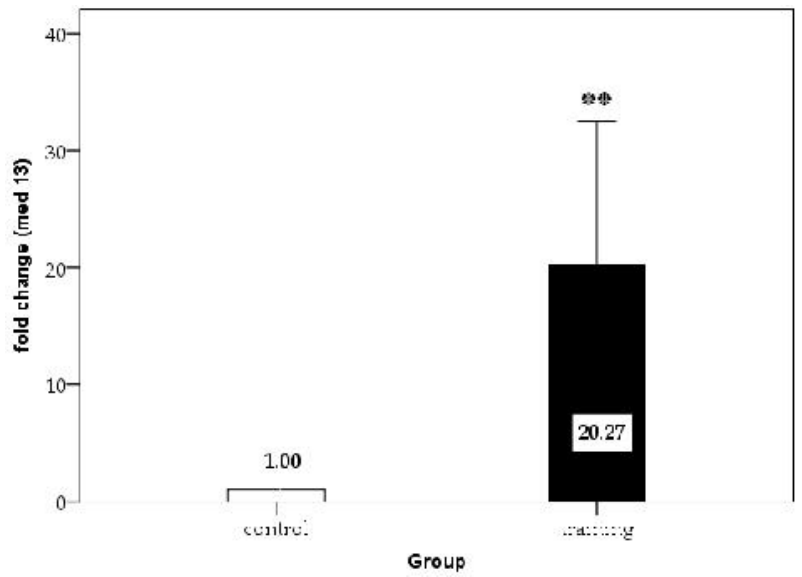

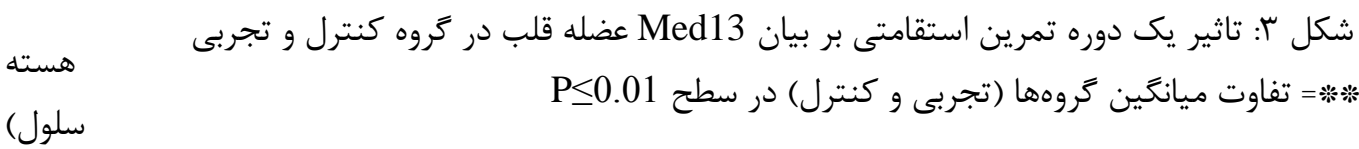


همجنين اين تحقيق نتوانست ميزان يروتئين MHC نوع آلفا و همجنين ميزان يروتئين med13 كه در حقيقت واحدهاى عملكردى تغييرات زنى مى باشند را اندازه كيرى

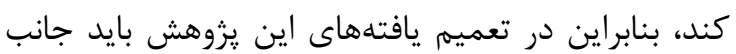

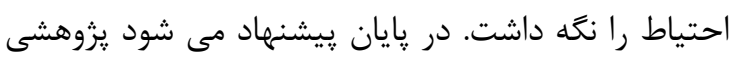

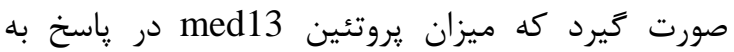
فعاليت استقامتى در قلب را اندازهيرى كنين كند

\section{نتيجه تيرى نيك}

با توجه به تاثير فعاليتهاى استقامتى بر اندازه توده بطن

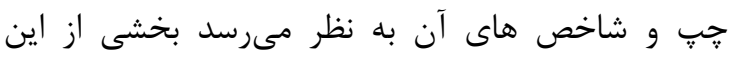

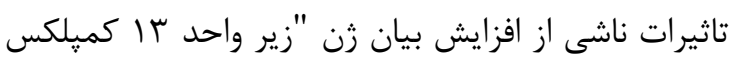
واسطه"باشد و از اين طريق بافت قلب به فعاليت هاى

$$
\text { استقامتى ياسخ مى دهد. }
$$

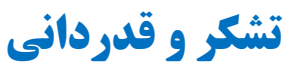

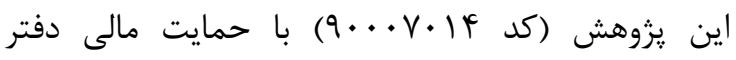
حمايت از طرحهاى يزوهشى رياست جمهورى انجام شد.
كه آنها را تحت عنوان (TR') مى شناسند عمل مى كند

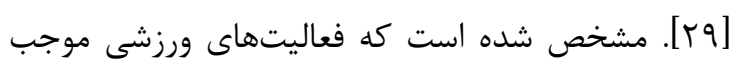
بهببود كاركرد گيرنده هاى بتا يك و آلفا يك هورمون

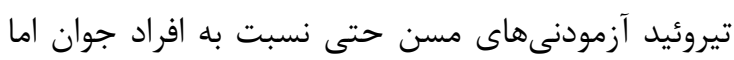

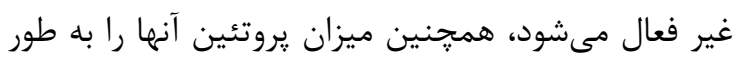

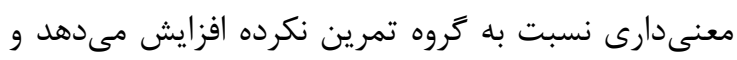

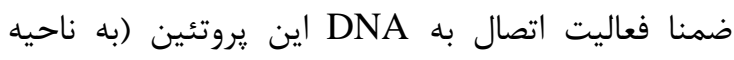

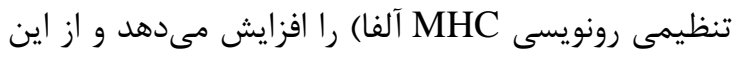

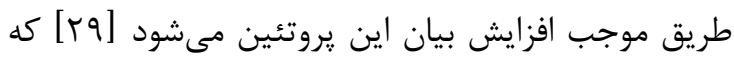

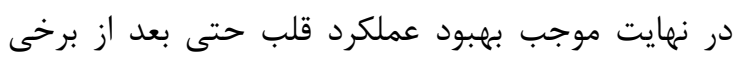

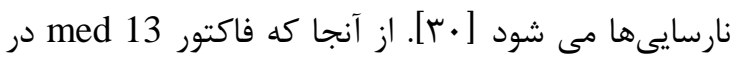

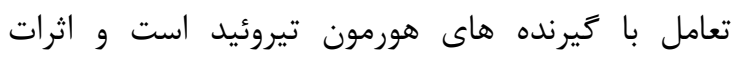

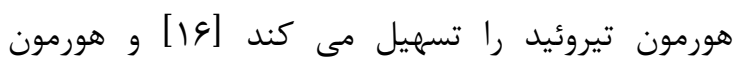

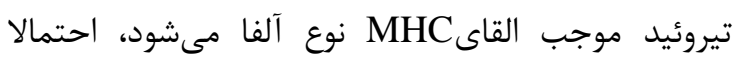

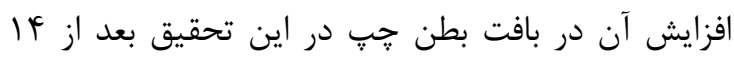

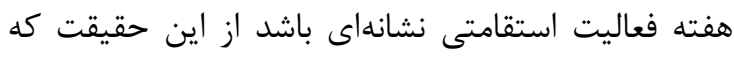
فعاليت بدنى با افزايش اين ميانجى اثرات هورمون تيروئيد

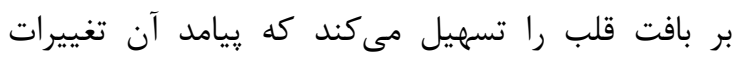

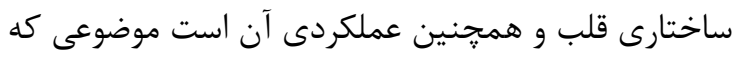

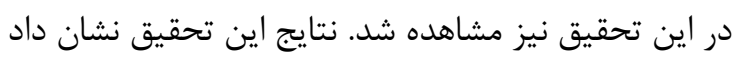

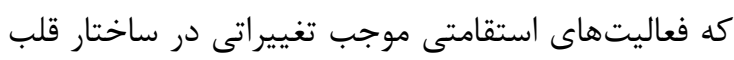

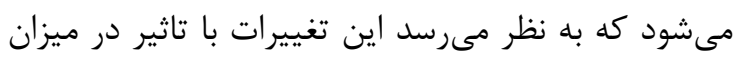

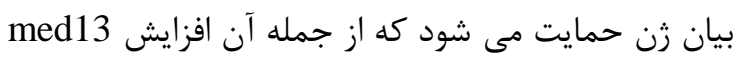

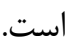
در يى فعاليت بدنى كه منجر به هاييرتروفى قلب مىشود

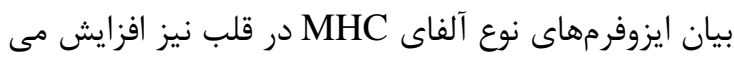
يابد [19] و فعاليت ATPase ايزوفرم نوع آلفايروتئين بيشتر است، به همين دليل سرعت كوتاهشدن

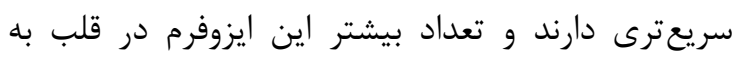

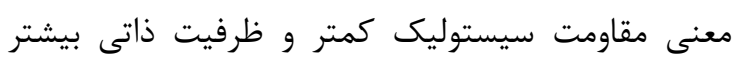
براى ايجاد جريان خون است [اسب] اما مقادير اين ايزوفرم

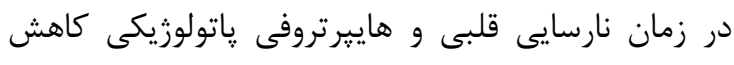

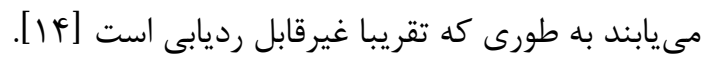

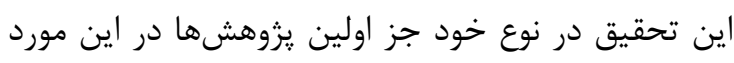
بود بنابراين عدم تحقيقاتى مشابه جهت مقايسه نتايج اين اين

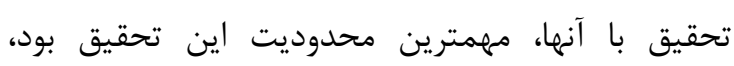

\section{1- Thyroid Hormone}




\section{References}

1. Fathi M, Rahmani Nia F, Moradpoorian MR, Asgari M, Rezaee R, The Relationship between Maximum Aerobic Power and Coronary Heart Disease Risk Factors, World Journal of Sport Sciences 2009;2(1): 01-6.

2. Fathi M, Gharakanlou R, Abroun S, Mokhtari-Dizaji M, Rezaei R, The evaluation of cardiac changes following endurance training in male Wistar rats, yafteh (in persian). 2014;15(5):11223[Persian].

3. Fathi M, Gharakanlou R, Rezaei R, The Effect of 14-Week Endurance Training on Left Ventricle HDAC4 Gene Expression of Wistar Male Rat, Journal of Sport in Biomotor Sciences 2014;11(1):115[Persian].

4. Pinho RA, Pinho CA, Tromm CB, Pozzi BG, Souza DR, Silva LA, "et al", Changes in the cardiac oxidative metabolism induced by PGC-1\{alpha\}: response of different physical training protocols in infarction-induced rats, Int J Cardiol 2013;168(4):4560-2.

5. Hill JA, Olson EN, Cardiac plasticity, N Engl J Med. 2008;358(13):1370-80.

6. Weiner RB, Baggish AL, Exercise-induced cardiac remodeling, Progress in cardiovascular diseases 2012;54(5):380-6.

7. Pluim BM, Zwinderman AH, van der Laarse A, van der Wall EE, The athlete's heart: a metaanalysis of cardiac structure and function,Circulation 2000;101(3):336-44.

8. Farup J, Kjolhede T, Sorensen H, Dalgas U, Moller AB, Vestergaard PF," et al", Muscle morphological and strength adaptations to endurance vs. resistance training, J Strength Cond Res. 2012;26(2):398-407.

9. D'Andrea A, Limongelli G, Caso P, Sarubbi B, Della Pietra A, Brancaccio P, "et al", Association between left ventricular structure and cardiac performance during effort in two morphological forms of athlete's heart, Int J Cardiol 2002;86(2-3):177-84.

10.Weeks KL, McMullen JR,The athlete's heart vs. the failing heart: can signaling explain the two distinct outcomes? Physiology (Bethesda) 2011;26(2):97-105.

11.Heineke J, Molkentin JD. Regulation of cardiac hypertrophy by intracellular signalling pathways, Nat Rev Mol Cell Biol. 2006;7(8):589-600.

12.Konopka AR, Trappe TA, Jemiolo B, Trappe SW, Harber MP, Myosin heavy chain plasticity in aging skeletal muscle with aerobic exercise training, The journals of gerontology Series A, Biological sciences and medical sciences 2011;66(8):835-41.

13. Swynghedauw B, Developmental and functional adaptation of contractile proteins in cardiac and skeletal muscles, Physiol Rev. 1986;66(3):710-71.

14. Miyata S, Minobe W, Bristow MR, Leinwand LA, Myosin heavy chain isoform expression in the failing and nonfailing human heart, Circ Res. 2000;86(4):386-90.

15.Belakavadi M, Fondell JD, Role of the mediator complex in nuclear hormone receptor signaling, Reviews of physiology, biochemistry and pharmacology 2006;156:23-43.

16.Ito M, Roeder RG, The TRAP/SMCC/Mediator complex and thyroid hormone receptor function, Trends Endocrinol Metab. 2001;12(3):127-34.

17.Ciloglu F, Peker I, Pehlivan A, Karacabey K, Ilhan N, Saygin O, "et al", Exercise intensity and its effects on thyroid hormones, Neuro Endocrinol Lett. 2005;26(6):830-4.

18. Fazio S, Palmieri EA, Lombardi G, Biondi B, Effects of thyroid hormone on the cardiovascular system, Recent Prog Horm Res. 2004;59:31-50.

19.Jin H, Yang R, Li W, Lu H, Ryan AM, Ogasawara AK, "et al",Effects of exercise training on cardiac function, gene expression, and apoptosis in rats, Am J Physiol Heart Circ Physiol, 2000;279(6):2994-3002.

20.Sun L, Shen W, Liu Z, Guan S, Liu J, Ding S, Endurance exercise causes mitochondrial and oxidative stress in rat liver: effects of a combination of mitochondrial targeting nutrients, Life Sci. 2010;86(1-2):39-44.

21.Farriol M, Rossell J, Schwar S, Body surface area in Sprague-Dawley rats. Journal of Animal Physiology and Animal Nutrition 1997; 77 (0931-2439):61-5. 
22.Tang H, Macpherson P, Marvin M, Meadows E, Klein WH, Yang XJ,“ et al”, A histone deacetylase 4/myogenin positive feedback loop coordinates denervation-dependent gene induction and suppression, Mol Biol Cell 2009;20(4):1120-31.

23. Silver N, Cotroneo E, Proctor G, Osailan S, Paterson KL, Carpenter GH, Selection of housekeeping genes for gene expression studies in the adult rat submandibular gland under normal, inflamed, atrophic and regenerative states, BMC Mol Biol. 2008;9:64.

24. Yuan JS, Reed A, Chen F, Stewart CN, Jr, Statistical analysis of real-time PCR data, BMC Bioinformatics 2006;7:85.

25.Wong ML, Medrano JF, Real-time PCR for mRNA quantitation, Biotechniques 2005;39(1):75-85. 26. Gunning P, O'neill G, Hardeman E, Tropomyosin-based regulation of the actin cytoskeleton in time and space, Physiological reviews 2008;88(1):1-35.

27.Pfaffl MW, A new mathematical model for relative quantification in real-time RT-PCR, Nucleic Acids Res. 2001;29(9):45.

28.Scharhag J, Schneider G, Urhausen A, Rochette V, Kramann B, Kindermann W, Athlete's heart: right and left ventricular mass and function in male endurance athletes and untrained individuals determined by magnetic resonance imaging, J Am Coll Cardiol. 2002;40(10):1856-63.

29.Iemitsu M, Miyauchi T, Maeda S, Tanabe T, Takanashi M, Matsuda M, "et al", Exercise training improves cardiac function-related gene levels through thyroid hormone receptor signaling in aged rats, Am J Physiol Heart Circ Physiol 2004;286(5):H1696-705.

30.Haykowsky MJ, Liang Y, Pechter D, Jones LW, McAlister FA, Clark AM, A Meta-Analysis of the Effect of Exercise Training on Left Ventricular Remodeling in Heart Failure Patients: The Benefit Depends on the Type of Training Performed, Journal of the American College of Cardiology, 2007;49(24):2329-36.

31.Barany M,ATPase activity of myosin correlated with speed of muscle shortening, The Journal of general physiology 1967;50(6):Suppl:197-218. 


\title{
Increase of the rate of "mediator complex subunit 13" gene expression in left ventricle due to endurance activity
}

\author{
Fathi $M^{l}$, Abroun $S^{2} *$ \\ ${ }^{1}$ Assistant professor, Physical Education Department, Lorestan University, Khorramabad, Iran. \\ ${ }^{2}$ Associate professor, Hematology Department, Tarbiat Modares University, Tehran, Iran. \\ *Corresponding Author: Tarbiat Modares University, Tehran, Iran. \\ Email: abroun@modares.ac.ir
}

\section{Abstract}

Background \& Objective: Endurance activity and "mediator complex subunit 13" significantly influence on structure and tissue of heart. The purpose of this study was to investigate the effects of a long time endurance activity program on "mediator complex subunit 13" gene expression in the left ventricle.

Materials and Methods: 14 rats under controlled conditions were housed and after familiarization randomly were assigned into control and Experimental groups, the experimental group performed an endurance activity program (14 weeks) on motorized treadmill, and then 48 hours after the end of the last session were anesthetized and sacrificed. The left ventricle of the heart was removed. Real time RT-PCR method was used to determine the expression levels of "mediator complex subunit 13" gene in the left ventricle. Finally $t$-test was used to evaluate collected data.

Results: The results of this research showed, physical activity not only influences on heart weight indices, but also it enhances "mediator complex subunit 13"gene expression in left ventricle of trained rats.

Conclusions: Given to the effects of endurance activity on the size of left ventricle and its indices, it seems part of these effects were related to "mediator complex subunit 13 " gene expression.

Keyword:"mediator complex subunit 13"gene, endurance activity, left ventricle 